Article

\title{
Detection of Copper(II) Ions Using Glycine on Hydrazine-Adsorbed Gold Nanoparticles via Raman Spectroscopy
}

\author{
Nguyễn Hoàng Ly ${ }^{1}$, Chulhun Seo ${ }^{2}$ and Sang-Woo Joo ${ }^{1,2, *}$ \\ 1 Department of Chemistry, Soongsil University, Seoul 156-743, Korea; nguyenhoangly2007@gmail.com \\ 2 Department of Information Communication, Materials, and Chemistry Convergence Technology, \\ Soongsil University, Seoul 156-743, Korea; chulhun@ssu.ac.kr \\ * Correspondence: sjoo@ssu.ac.kr; Tel.: +82-2-820-0434
}

Academic Editors: Jong Seung Kim and Min Hee Lee

Received: 19 August 2016; Accepted: 13 October 2016; Published: 26 October 2016

\begin{abstract}
A facile, selective, and sensitive detection method for the $\mathrm{Cu}^{2+}$ ions in environmental and biological solutions has been newly developed by observing the unique CN stretching peaks at $\sim 2108 \mathrm{~cm}^{-1}$ upon the dissociative adsorption of glycine (GLY) in hydrazine buffer on gold nanoparticles (AuNPs). The relative abundance of $\mathrm{Cu}$ species on AuNPs was identified from X-ray photoelectron spectroscopy analysis. UV-Vis spectra also indicated that the Au particles aggregated to result in the color change owing to the destabilization induced by the GLY-Cu ${ }^{2+}$ complex. The $\mathrm{CN}$ stretching band at $\sim 2108 \mathrm{~cm}^{-1}$ could be observed to indicate the formation of the CN species from GLY on the hydrazine-covered AuNP surfaces. The other ions of $\mathrm{Fe}^{3+}, \mathrm{Fe}^{2+}, \mathrm{Hg}^{2+}, \mathrm{Mg}^{2+}, \mathrm{Mn}^{2+}$, $\mathrm{Ni}^{2+}, \mathrm{Zn}^{2+}, \mathrm{Cr}^{3+}, \mathrm{Co}^{2+}, \mathrm{Cd}^{2+}, \mathrm{Pb}^{2+}, \mathrm{Ca}^{2+}, \mathrm{NH}_{4}{ }^{+}, \mathrm{Na}^{+}$, and $\mathrm{K}^{+}$at high concentrations of $50 \mu \mathrm{M}$ did not produce such spectral changes. The detection limit based on the $\mathrm{CN}$ band for the determination of the $\mathrm{Cu}^{2+}$ ion could be estimated to be as low as $500 \mathrm{nM}$ in distilled water and $1 \mu \mathrm{M}$ in river water, respectively. We attempted to apply our method to estimate intracellular ion detection in cancer cells for more practical purposes.
\end{abstract}

Keywords: $\mathrm{Cu}(\mathrm{II})$; Raman spectroscopy; $\mathrm{C} \equiv \mathrm{N}$ stretching mode; gold nanoparticles; glycine; intracellular imaging

\section{Introduction}

Nanomaterial-based tools have been successfully implemented to monitor heavy metal ions [1]. By using nanomaterials, surface-enhanced Raman scattering (SERS) has provided one of the most sensitive methods on noble metal surfaces [2,3]. Selection of suitable reducing reagents is significant in the preparation of well-dispersed particles to study nanometric objects [4]. SERS has opened up novel opportunities in analytics to provide a vibrational fingerprint with high spectral resolution [5]. Nanoparticles have been used to detect a trace amount of analytes [6,7]. Various techniques have currently been developed for the imaging of the metal ions [8]. Inductively coupled plasma mass spectrometry is practically a powerful method that has been developed for metal ion detection [9]. However, it remains challenging to develop a novel analytical method for cheaper and easier metal ion monitoring.

At elevated concentrations, $\mathrm{Cu}^{2+}$ ions are toxic in fundamental biological processes and can cause damage to organs such as the liver and kidneys [10]. This potential hazard makes it indispensable to monitor the amount of copper in environmental water. Toward alleviating this issue, the selective detection of $\mathrm{Cu}^{2+}$ ions in aqueous solutions with high sensitivity is of great importance. To ensure safety, a detection limit as low as $20 \mu \mathrm{M}(1.3 \mathrm{ppm})$ is recommended by the Environmental Protection Agency 
(EPA) [11]. Recently, ZnO@ZnS core-shell nanoparticles [12] and fluorescent gold nanoclusters [13] have been introduced to achieve efficient and selective detection of $\mathrm{Cu}^{2+}$ ions. Functionalized gold nanoparticles (AuNPs) [14] were also used for the detection of metal ions including $\mathrm{Cu}^{2+}$. SERS has also been used to discriminate $\mathrm{Cu}^{2+}$ ions in aqueous solutions with an interference of $\mathrm{Hg}^{2+}$ and $\mathrm{Co}^{2+}[15,16]$.

Glycine (GLY), one of the simplest amino acids, was known to adsorb on metal surfaces $[17,18]$ via the carboxylate or the amino groups. GLY was predicted to bind the $\mathrm{Cu}^{2+}$ ion as a dimeric form [19]. Using an infrared spectroscopy tool, GLY was reported to dissociate to produce the cyanide group under alkaline $\mathrm{pH}$ conditions, when a positive voltage was applied to a gold electrode surface [20]. Cyanide bands at ca. $2100 \mathrm{~cm}^{-1}$ have been utilized as a marker band because of their discriminating position in the vibrational spectral window without the interference of multiple overlapping bands between 1000 and $1700 \mathrm{~cm}^{-1}$ [21,22]. In view of such electrochemical reactions [20], GLY may provide a unique marker of the cyanide group on metal surfaces.

In this study, we report a new $\mathrm{Cu}^{2+}$ ion detection method by means of SERS of GLY on AuNPs. $\mathrm{UV}$-Vis absorption and a colorimetric method are also introduced to check the $\mathrm{Cu}^{2+}$-induced surface change. The variation of surface charge is characterized by means of zeta potential measurements. The cyanide band became prominent upon the increase of the $\mathrm{Cu}^{2+}$ ion in the GLY complex. This is the first study based on the selective detection of the $\mathrm{Cu}^{2+}$ ion using the dissociative adsorption of GLY on AuNPs that produces cyanide peaks whose intensities may be correlated with the $\mathrm{Cu}^{2+}$ ion concentration. Moreover, micromolar sensitivity could be achieved without the interferences of 15 ionic species including $\mathrm{Hg}^{2+}$ and $\mathrm{Co}^{2+}$ observed in the previous Raman studies $[15,16]$. These results may be useful in the development of a novel detection scheme to improve the efficacy of conventional methods. This study aims to develop a simple and inexpensive discrimination method for $\mathrm{Cu}^{2+}$ ions by applying AuNP-based sensors.

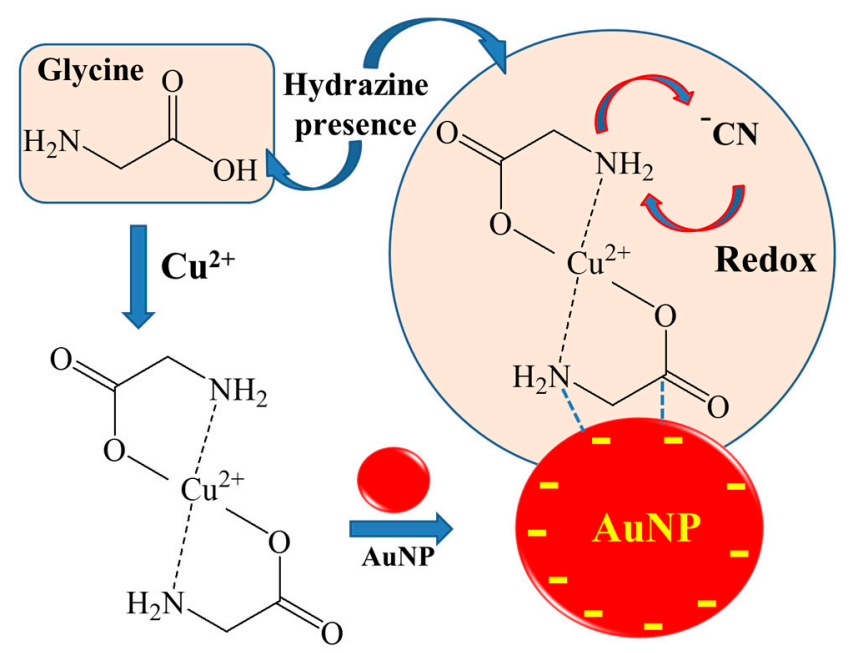

Figure 1. Schematic diagram of detection of $\mathrm{Cu}^{2+}$ ions due to the redox properties to lead the dissociation of GLY into the CN group on AuNP surfaces in the presence of hydrazine. The GLY-Cu ${ }^{2+}$ complex based on reference [19]. The increase of $\left[\mathrm{Cu}^{2+}\right]$ results in more positive redox properties of the GLY-Cu ${ }^{2+}$ complex and stronger $\mathrm{CN}$ intensities.

Figure 1 shows our experimental scheme to detect $\mathrm{Cu}^{2+}$ ions with the complex of GLY in the presence of the hydrazine buffer, and subsequent adsorption on citrate-coated AuNPs. A dissociative reaction of GLY was found at higher concentrations of copper ions. By assembling and annealing the $\mathrm{Cu}^{2+}$ and GLY first in the hydrazine buffer, the complex can be ready to adsorb on AuNPs. We found that the $\mathrm{Cu}^{2+}$ ion made the surface charge of AuNPs more positive. On positively charged Au surfaces, GLY was dissociated to produce the cyanide ions, which were adsorbed on AuNPs. These 
reactions occurred under alkaline hydrazine buffer conditions at $\mathrm{pH} \sim 9.2$. As control experiments, we tested the different amino acid such as alanine instead of GLY and performed independent trials using hydrazine, GLY, and $\mathrm{NaOH}$ with the same concentration and the $\mathrm{pH}$ value of $\sim 9.2$ without the commercial hydrazine buffer containing 0.6 M GLY, $0.5 \mathrm{M}$ hydrazinium sulphate and $0.0375 \%$ chloroform. The CN peaks could not be observed without either GLY or the commercial hydrazine buffer. We found that the $\mathrm{CN}$ peaks decreased significantly after $99.999 \%$ nitrogen-gas bubbling for $10 \mathrm{~min}$, although not shown here. Despite the possible existence of the oxygen species, the ambient air may affect the redox reactions to produce the $\mathrm{CN}$ peaks under our experiment conditions.

\section{Experimental Section}

\subsection{Materials}

GLY buffer solution (0.6 M, pH 9.2, Catalogue \#G5418) containing $0.5 \mathrm{M} \mathrm{NH}_{2} \mathrm{NH}_{2}$ and $0.0375 \%$ chloroform and the other ionic (mostly nitrate) substances of $\mathrm{Cu}\left(\mathrm{NO}_{3}\right)_{2}, \mathrm{Fe}\left(\mathrm{NO}_{3}\right)_{3}, \mathrm{Fe}\left(\mathrm{C}_{2} \mathrm{O}_{4}\right), \mathrm{Hg}\left(\mathrm{NO}_{3}\right)_{2}$, $\mathrm{Mg}\left(\mathrm{NO}_{3}\right)_{2}, \mathrm{Mn}\left(\mathrm{NO}_{3}\right)_{2}, \mathrm{Ni}\left(\mathrm{NO}_{3}\right)_{2}, \mathrm{Zn}\left(\mathrm{NO}_{3}\right)_{2}, \mathrm{Cr}\left(\mathrm{NO}_{3}\right)_{3}, \mathrm{Co}\left(\mathrm{NO}_{3}\right)_{2}, \mathrm{Cd}\left(\mathrm{NO}_{3}\right)_{2}, \mathrm{~Pb}\left(\mathrm{NO}_{3}\right)_{2}, \mathrm{Ca}\left(\mathrm{NO}_{3}\right)_{2}$, $\mathrm{NH}_{4} \mathrm{NO}_{3}, \mathrm{NaCl}$, and $\mathrm{KNO}_{3}$, as the forms of either the hydrates or the nonhydrates, were purchased from Sigma Aldrich (St. Louis, MO, USA). GLY (99\%) and hydrazine solution (35 wt \% in $\mathrm{H}_{2} \mathrm{O}$ ) were also obtained from Sigma Aldrich. Human cervical carcinoma HeLa (ATCC ${ }^{\circledR}$ CCL-2) cells were grown on Dulbecco Modified Eagle Medium in a steri-cycle $\mathrm{CO}_{2}$ incubator (Thermo Fisher Scientific) in $5 \% \mathrm{CO}_{2} / 95 \%$ humidified air at $37^{\circ} \mathrm{C}$. Cell culture media were supplemented with $1 \%$ penicillin-streptomycin antibiotics (Gibco) $/ 0.2 \mathrm{ppm}$ plasmocin and $10 \%$ fetal bovine serum (FBS).

\subsection{Instrumentations}

We performed dark-field microscopy (DFM) [23] in cancer cells to check the possibility to apply our method under physiological conditions. We used the zeta potentials, transmission electron microscopy (TEM), energy dispersive X-ray analysis (EDAX), UV-Vis absorption spectroscopy, and SERS to characterize the AuNP suspensions. UV-Vis absorption spectra of the AuNP suspension were used to observe spectral changes with a Mecasys 3220 PC spectrophotometer. Surface charges were measured by zeta potential kits (Otsuka ELZ-2). High-resolution (HR)-TEM (JEOL JEM-3100) was used to observe the morphology of the AuNP Aggregates. EDAX spectrometer measurements were performed to find the $\mathrm{Cu}$ species assembled on Ni-coated grids by GLY-Cu${ }^{2+}$ on metal nanoparticles using a Tecnai TF30 ST field emission TEM (300 kV). X-ray photoelectron spectroscopy (XPS) was conducted using a Sigma Probe Instrument Thermo VG spectrometer with an X-ray source of monochromic Al X-ray sources (Al K $\alpha$ line: $1486.6 \mathrm{eV}$ ). The resolution of the full width at half-maximum is $0.76 \mathrm{eV}$ in the $\mathrm{Au}$ $3 d_{5 / 2}$ peaks.

\subsection{Preparation of AuNPs and GLY-Cu ${ }^{2+}$ Complex}

We found that the $40 \mathrm{~nm}$ AuNPs (Catalogue \# EMGC40/4) from BBI solutions (Cardiff, UK) would show the strongest $\mathrm{CN}$ species under our experimental conditions. For the UV-Vis experiment, in the first step, GLY $(0.6 \mathrm{M}, 10 \mu \mathrm{L}), \mathrm{Cu}^{2+}(1 \mathrm{mM}, 50 \mu \mathrm{L})$, and ultrapure water $(800 \mu \mathrm{L})$ were put into a $1.5 \mathrm{~mL}$ Eppendorf tube, stirred and stabilized over $60 \mathrm{~min}$ at room temperature. In the second step, $140 \mu \mathrm{L}$ of AuNPs was added to the GLY-Cu ${ }^{2+}$ complex. Excessive amounts of GLY and hydrazine in the sample solutions were not found to disturb the presented ion detection scheme.

For the zeta potential experiment, $10 \mu \mathrm{L} \mathrm{Cu}{ }^{2+}(0.1 \mu \mathrm{M})$ and $50 \mu \mathrm{L}$ GLY $(0.6 \mathrm{M})$ were mixed and stirred for over $60 \mathrm{~min}$ at room temperature. Subsequently, $140 \mu \mathrm{L}$ of the AuNP solution was added to the sample mixture and the surface charges of AuNPs appeared to shift toward the positive value after the addition of $10 \mathrm{nM}$ of the $\mathrm{Cu}^{2+}$ ion by measuring zeta potentials.

$1.0 \mathrm{~mL}$ of the resulting mixture solution was placed in a $1.5 \mathrm{~mL}$ centrifugal tube for the XPS experiment. The AuNPs-GLY-Cu ${ }^{2+}$ sample was collected by $4{ }^{\circ} \mathrm{C}$ centrifugation at $10,000 \mathrm{rpm}$ for $10 \mathrm{~min}$. After the supernatant parts were removed up to a residual volume of $20 \mu \mathrm{L}$, the $20 \mu \mathrm{L}$ 
sample of AuNPs-GLY-Cu ${ }^{2+}$ was dropped on a $5 \mathrm{~mm} \times 5 \mathrm{~mm}$ cover glass purchased from Deckgläser (Sondheim/Rhön, Germany). The sample was then dried at $75{ }^{\circ} \mathrm{C}$ overnight.

For the SERS experiment, $10 \mu \mathrm{L}$ of $\mathrm{Cu}^{2+}(1 \mathrm{mM}$, in either distilled water or river water) and $50 \mu \mathrm{L}$ of GLY (0.6 M, GLY buffer solution, $\mathrm{pH}$ 9.2) were mixed and stirred at room temperature for over $1 \mathrm{~h}$. Subsequently, $140 \mu \mathrm{L}$ of AuNPs was added to the mixture to examine the adsorption of $\mathrm{GLY}^{-\mathrm{Cu}^{2+}}$ on AuNPs by recording the SERS spectra of the samples. The $\mathrm{pH}$ value was measured to be 8.9 in all the SERS measurements. Since we had used the GLY buffer solution with the fixed values of initial GLY $0.6 \mathrm{M}$ and $0.5 \mathrm{M}$ hydrazine at $\mathrm{pH} 9.2$, it was difficult to control the relative concentrations of GLY and hydrazine to maintain the identical $\mathrm{pH}$ values and reaction conditions.

GLY exhibited an increasing Raman intensity correlated to $\left[\mathrm{Cu}^{2+}\right]$ in water $(50 \mu \mathrm{M})$ on AuNPs. Response behaviors were examined for GLY in the potential interference of various metal ions on AuNPs. The Raman spectral features of GLY-M ${ }^{\mathrm{n}+}$ on AuNPs were unchanged in the presence of $\mathrm{Fe}^{3+}, \mathrm{Fe}^{2+}, \mathrm{Hg}^{2+}, \mathrm{Mg}^{2+}, \mathrm{Mn}^{2+}, \mathrm{Ni}^{2+}, \mathrm{Zn}^{2+}, \mathrm{Cr}^{3+}, \mathrm{Co}^{2+}, \mathrm{Cd}^{2+}, \mathrm{Pb}^{2+}, \mathrm{Ca}^{2+}, \mathrm{NH}_{4}^{+}, \mathrm{Na}^{+}$, and $\mathrm{K}^{+}$(all at concentrations of $50 \mu \mathrm{M}$ ). Of all the tested metal ions, only $\mathrm{Cu}^{2+}$ ions increased the Raman intensity in the presence of GLY on AuNPs.

Inductively coupled plasma optical emissions spectrometry (ICP-OES) was used to estimate the atomic compositions of the prepared samples with an ICAP-7400 analyzer from Thermo Scientific (Waltham, MA, USA) except the Hg measurements by a CETAC M-7500 mercury analyzer from Parma Company (Omaha, NE, USA). Triply-distilled water was used to test the ionic detection. In order to check the applicability of our analytical methodology, the river water samples were obtained from Han river (Seoul, Korea), respectively. Raman spectra for ionic detection in environmental samples were obtained as in the method of our recent report [24-26].

\section{Results and Discussion}

\subsection{Physical Characterization}

To understand the surface reactions, AuNPs were characterized by HR-TEM and XPS. The sizes of the AuNPs are $\sim 40 \mathrm{~nm}$, as shown in the TEM image in Figure 2a. We could also find a trace amount of the $\mathrm{Cu}$ species on AuNPs by EDAX. The relative abundance of the adsorbed $\mathrm{Cu}$ species on metal NPs could be found to be as low as $0.2 \%-0.6 \%$. As shown in Figure 2, XPS data [27] also confirmed that the percentage of $\mathrm{Cu}$ is as low as $0.2 \%$. Because of a small amount of the $\mathrm{Cu}$ species below $1 \%$, we could not map the $\mathrm{Cu}$ distribution on a single nanoparticle.

By adding GLY, the surface charge became slightly more negative. Zeta potential measurements indicated that the surface charges appeared to become positive and almost neutral to destabilize the colloidal conditions and induce aggregation in the presence of $\mathrm{Cu}^{2+}$ ions, as is consistent with the UV-Vis data. This result suggests that the high concentration of may oxidize the GLY complex on the metal nanoparticle surfaces. On the basis of the surface characterization on AuNPs, we attempted to monitor $\mathrm{Cu}^{2+}$ ions by Raman spectroscopy.

Figure 2c shows the color change of AuNPs upon the increase of the $\mathrm{Cu}^{2+}$ ion concentrations. As the concentration of $\mathrm{Cu}^{2+}$ ions increased in the complexes, the UV-Vis absorption band at 600-900 nm became stronger, indicating the aggregation of AuNPs. It has to be mentioned that AuNPs intrinsically have negative charges. As shown in Figure 2c, the SPR bands of AuNPs are newly presented instead of those of AgNPs. The decrease in the SPR bands at $520 \mathrm{~nm}$ may be caused not by the destruction of the nanoparticles but by the increase in particle sizes owing to aggregation. Instead, we observed extensive shifts of the SPR band between 600 and $900 \mathrm{~nm}$ to support the evidence of interparticle aggregation.

To address the aggregation issue, we newly performed the dynamic light scattering measurements as shown in Figure 2d. Since the static TEM measurements may not provide good information on the aggregation during the sample preparation process, as solution evaporation may induce particle aggregation owing to dryness on the sample grid, we performed light scattering measurements to 
estimate the hydrodynamic diameters of the aggregated AuNPs in aqueous solutions to better address the issue of aggregation in relation to SERS intensities. At $\left[\mathrm{Cu}^{2+}\right]=1$ and $50 \mu \mathrm{M}$, the diameters became 240 and $640 \mathrm{~nm}$, respectively, to suggest an extensive aggregation mediated by the Cu ion species, which should result in strong SERS effects.

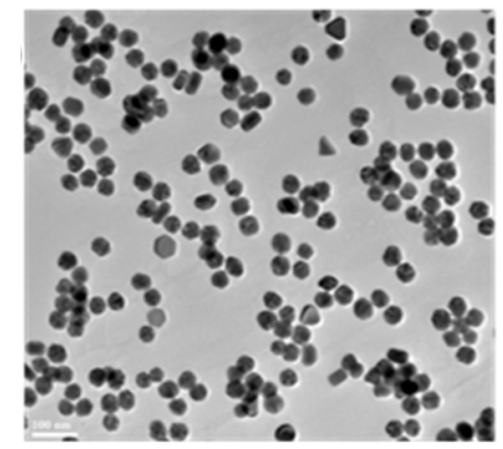

(a)

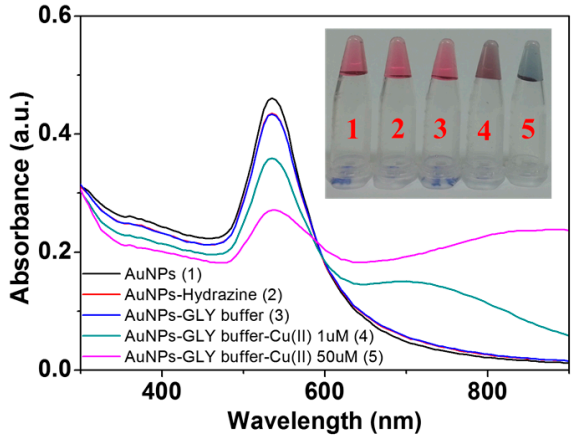

(c)

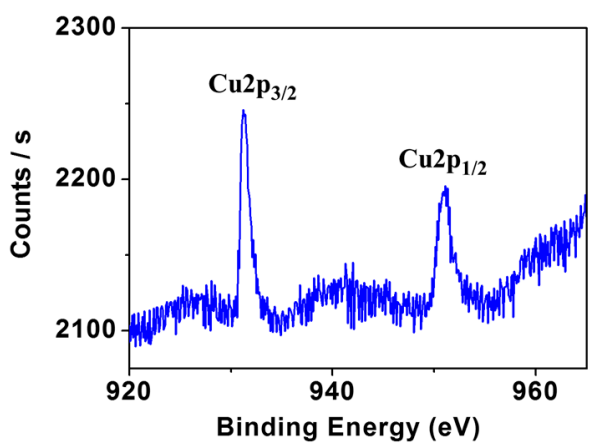

(b)

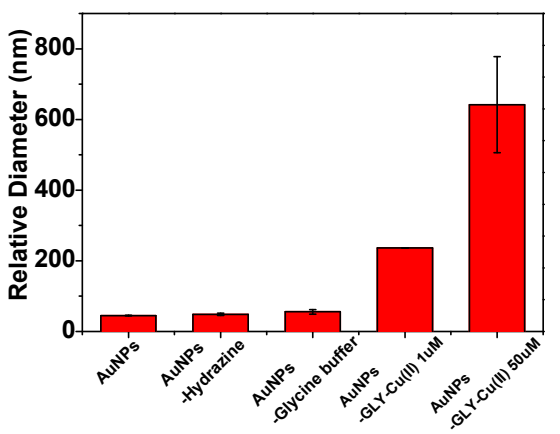

(d)

Figure 2. (a) TEM image and (b) XPS spectrum of GLY-Cu ${ }^{2+}$ on AuNPs; (c) UV-Vis absorption spectra. The inset shows a photo of the AuNP solutions in the (1) absence and (2) presence of hydrazine, (3) glycine buffer and glycine buffer- $\mathrm{Cu}^{2+}$ with $\left[\mathrm{Cu}^{2+}\right]=1$ and $50 \mu \mathrm{M}$ in (4) and (5), respectively; (d) Stick diagram of relative hydrodynamic diameters of $\mathrm{GLY}-\mathrm{Cu}^{2+}$ on AuNPs in the $\left[\mathrm{Cu}^{2+}\right]$ concentration range of 1 and $50 \mu \mathrm{M}$.

\subsection{Raman Spectra of Hydrazine and GLY on AuNPS}

Figure 3 shows the normal Raman (NR) and SERS spectra of GLY on AuNPs. The Raman spectrum of GLY is consistent with that reported previously [28-30]. It was found that most strong bands could be ascribed to the hydrazine peaks, as previously reported [31-33]. The SERS spectrum of GLY appeared to be relatively weak with its amino group interacting with Au surfaces. In the SERS spectrum of hydrazine on AuNPs, we could not observe a strong hydrazone linkage-related N-N stretching mode at $919 \mathrm{~cm}^{-1}$ or N-H bending modes at 1174 and $1222 \mathrm{~cm}^{-1}$ [34].

Since hydrazine shows weak basic properties in aqueous solution to form stable salts with a number of mineral acids such as hydrazine sulfate $\mathrm{N}_{2} \mathrm{H}_{5} \cdot \mathrm{HSO}_{4}$ and hydrazine hydrochloride $\mathrm{N}_{2} \mathrm{H}_{4} \cdot \mathrm{HCl}$, it may interact with the GLY amino acid efficiently. As suggested from the SERS spectrum of GLY in the presence of hydrazine as shown in Figure 3e, GLY can be decomposed to yield a CN peak even in the absence of $\mathrm{Cu}^{2+}$. A magnified view of Figure $3 \mathrm{f}$ in the presence of $\mathrm{Cu}^{2+}$ also exhibited the hydrazine peaks. As a control experiment without hydrazine, we could not observe any $\mathrm{CN}$ peaks. This result indicates a role of hydrazine to bind the amino acid as a base after adsorption on the metal nanoparticle surfaces. The other amino acids including methione, lysine, and leucine would not provide strong CN peaks as in the case of GLY. The simple structure of GLY along with the strong interaction with the $\mathrm{Cu}(\mathrm{II})$ ion may facilitate its dissociation to yield $\mathrm{CN}$ peaks on metal surfaces, whereas the reaction appears to be unfavorable to the other amino acid. Considering the high initial 
concentrations of both GLY $(0.6 \mathrm{M})$ and hydrazine $(0.5 \mathrm{M})$, we cannot exclude the interactions between hydrazine and $\mathrm{Cu}^{2+}$. As suggested from the SERS features of hydrazine in Figure $3 f$, it is likely that hydrazine adsorbed fairly strongly on $\mathrm{Au}$ to interact mainly with GLY. The increase of the $\mathrm{Cu}^{2+}$ ion was thought to lead a stabilization of the hydrazine-modified AuNPs.

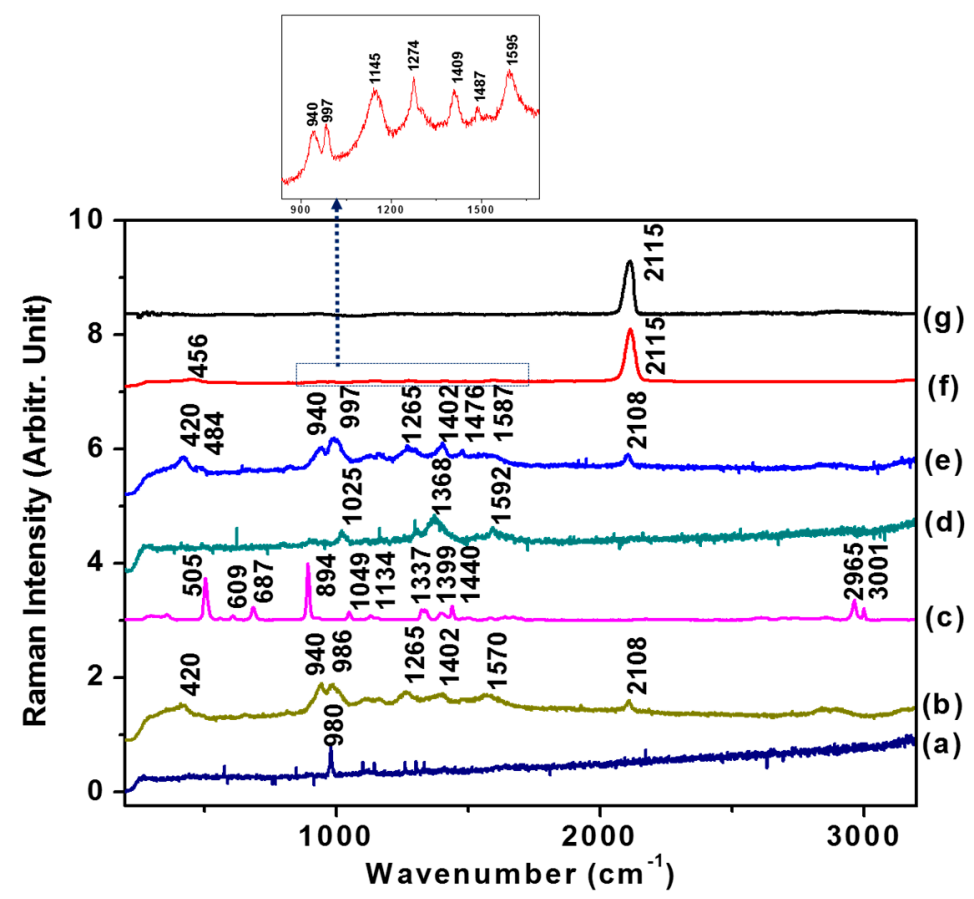

Figure 3. (a) NR of and (b) surface-enhanced Raman scattering (SERS) of hydrazine (wt. 35\% in $\mathrm{H}_{2} \mathrm{O}$ ) on AuNPs; (c) NR of GLY; (d) SERS of GLY on AuNPs; (e) SERS of GLY (hydrazine buffer) with $\left[\mathrm{Cu}^{2+}\right]=0$; (f) SERS of Gly (hydrazine buffer) with $\left[\mathrm{Cu}^{2+}\right]=50 \mu \mathrm{M}$. The inset shows a magnified view of the weak vibrational bands of hydrazine; (g) SERS spectrum of 0.1 M KCN on AuNPs.

It is noteworthy that the CN band at $\sim 2108 \mathrm{~cm}^{-1}$ was newly appeared in the SERS spectra. In the presence of $50 \mu \mathrm{M}$ of $\mathrm{Cu}^{2+}$ ions, the $\mathrm{CN}$ band became more intensified. The band position at $\sim 2108 \mathrm{~cm}^{-1}$ corresponds to the $\mathrm{CN}$ species adsorbed on Au surfaces, considering that this is almost identical to the $\mathrm{CN}$ band at $2115 \mathrm{~cm}^{-1}$ when $0.1 \mathrm{M} \mathrm{KCN}$ is treated on AuNPs, as demonstrated in Figure $3 g$.

Our result is consistent with the stoichiometric reaction [20] equations that the CN group may be formed on the surfaces under alkaline conditions. Furthermore, the decomposition of GLY at the positive surface charge is in agreement with this report [20]. Referring from the previous reports of the formation constants $[35,36]$ of GLY-Cu and metal-CN, it was expected that CN would strongly coordinate to the $\mathrm{Cu}$ ions. However, considering that only less than $1 \%$ of $\mathrm{Cu}$ (II) ions exist on nanoparticle surfaces in XPS measurements as suggested in Figure 2b, most CN bands may be ascribed to the AuCN mode.

We obtained the SERS spectra of GLY on alkaline AuNPs in the presence of various ions- $\mathrm{Fe}^{3+}$, $\mathrm{Fe}^{2+}, \mathrm{Hg}^{2+}, \mathrm{Mg}^{2+}, \mathrm{Mn}^{2+}, \mathrm{Ni}^{2+}, \mathrm{Zn}^{2+}, \mathrm{Cr}^{3+}, \mathrm{Co}^{2+}, \mathrm{Cd}^{2+}, \mathrm{Pb}^{2+}, \mathrm{Ca}^{2+}, \mathrm{NH}_{4}^{+}, \mathrm{Na}^{+}$, and $\mathrm{K}^{+}$-at the same concentrations of $50 \mu \mathrm{M}$, in comparison with $\mathrm{Cu}^{2+}$ as shown in Figure 4a. It was found that only $\mathrm{Cu}^{2+}$ ions strongly enhanced CN formation as illustrated in the stick diagram of Figure $4 \mathrm{~b}$. It is reported that $\mathrm{Au}$ and $\mathrm{Cu}$ can form a bimetallic structure [37]. Presumably, due to similar crystal structures and electronic properties, the $\mathrm{Cu}^{2+}$ ion may easily adsorb on AuNP surfaces instead of the other ions. 


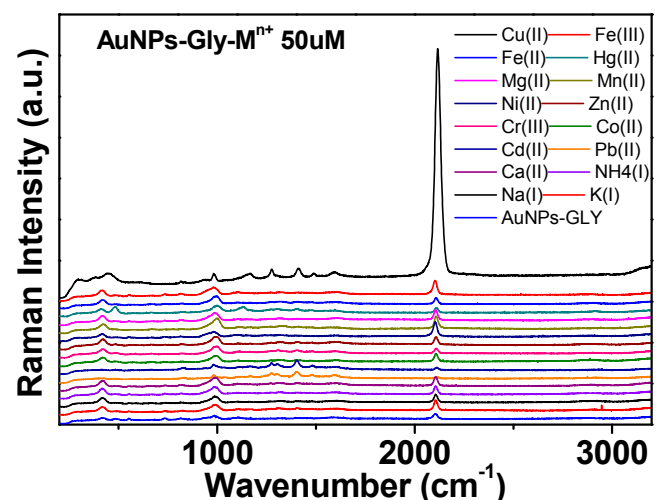

(a)

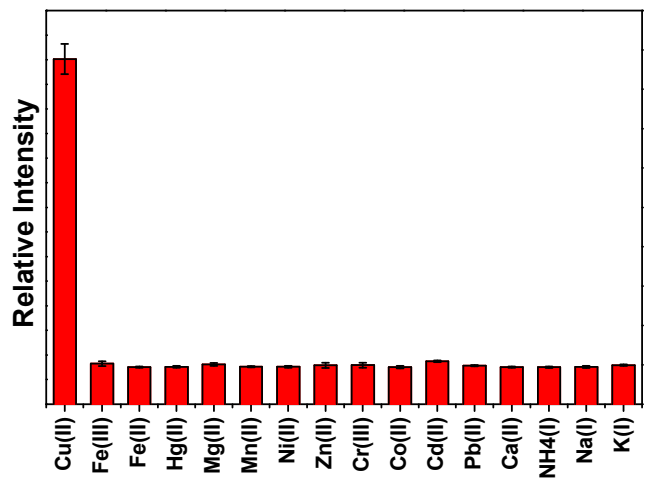

(b)

Figure 4. (a) SERS spectra of GLY in the presence of $50 \mu \mathrm{M}$ of various ions. The SERS spectrum of GLY on AuNPs is presented in the middle. Only the $\mathrm{Cu}^{2+}$ ion could induce a strong $\mathrm{CN}$ peak as listed at the top of the spectra; (b) Stick diagram of the relative intensities of the $\mathrm{CN}$ bands for the tested ions. Three independent measurements were performed to yield the error bars in order to check the reproducibility.

\subsection{CN Formation Reactions of GLY-Cu ${ }^{2+}$ on AuNPs and Selective Test}

Figure 5 shows SERS spectra of GLY depending on the $\mathrm{Cu}^{2+}$ concentration. It seems certain that the band at $\sim 2108 \mathrm{~cm}^{-1}$ can be ascribed to the $\mathrm{CN}$ species, referring from the unique band position. The $\mathrm{CN}$ stretching region depending on the $\mathrm{Cu}^{2+}$ concentrations was magnified between 2000 and $2200 \mathrm{~cm}^{-1}$ in Figure 5a. It revealed an increase in the band intensities depending on the $\mathrm{Cu}^{2+}$ ion concentration. It was found that the $\mathrm{CN}$ stretching band showed a rather asymmetric shape that could be decomposed into two bands at $\sim 2070$ and $\sim 2108 \mathrm{~cm}^{-1}$. It is not absolutely certain whether the weaker band may be ascribed to the $\mathrm{CN}$ mode on $\mathrm{Cu}$ and $\mathrm{Au}$ surfaces, depending on their close vibrational band positions [38]. Considering that only $\mathrm{KCN}$ also exhibited an asymmetric shape, the weaker shoulder peaks may suggest a different binding mode on Au surfaces. In the previous study [17], the peak positions of $\mathrm{CN}$ band appeared to blueshift as the applied potential become more positive. The CN peak became blueshifted from $\sim 2108 \mathrm{~cm}^{-1}$ to $\sim 2115 \mathrm{~cm}^{-1}$, as the concentrations of the $\mathrm{Cu}^{2+}$ ion increased, presumably due to more cationic environments.

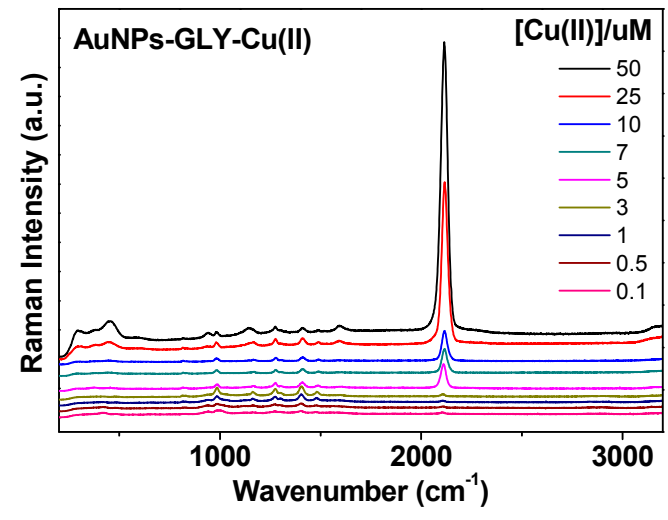

(a)

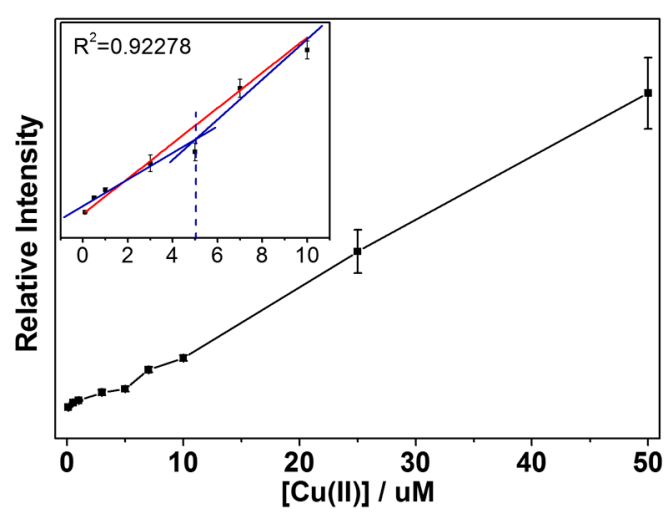

(b)

Figure 5. (a) Concentration-dependent SERS spectra of GLY depending on the $\left[\mathrm{Cu}^{2+}\right]$ concentration. Baseline corrections were made to compare the spectral bands; (b) Intensity plot of the $\mathrm{CN}$ intensities versus the $\left[\mathrm{Cu}^{2+}\right]$ concentration of $0-50 \mu \mathrm{M}$. The inset shows fitting the linear region between 0 and $10 \mu \mathrm{M}$. 
Figure $5 \mathrm{~b}$ shows an intensity plot of the $\mathrm{CN}$ stretching bands depending on the $\left[\mathrm{Cu}^{2+}\right]$ concentration range of $0-50 \mu \mathrm{M}$ in river water. The detection limit on the basis of the $\mathrm{CN}$ band is as low as $2 \mu \mathrm{M}$ of $\mathrm{Cu}^{2+}$ ions. The proposed detection limit was estimated from the linear fitting curve, where the spectral change could begin to occur based on the linear equation of $Y(\mathrm{CN}$ intensities $)=B$ (intercept) $+A$ (slope) $\times X\left(\mathrm{Cu}^{2+}\right.$ concentrations).

\subsection{CN Bands in River Water Samples Contacting Highly Concentrated $\mathrm{Na}, \mathrm{Ca}, \mathrm{Mg}$, and $\mathrm{K}$ Ions}

As proof of application, the concentrations of $\mathrm{Ca}, \mathrm{K}, \mathrm{Na}$, and $\mathrm{Mg}$, were found to be $\sim 31.04 \mathrm{ppm}$, $\sim 6.37 \mathrm{ppm}, \sim 25.19 \mathrm{ppm}$, and $\sim 5.77 \mathrm{ppm}$ for the river water sample [24-26]. As demonstrated in Figure 6, our analytical methodology of $\mathrm{Cu}^{2+}$ determination could be applied in real water samples only with higher limit of detection. It has to be mentioned that $\sim 2 \mu \mathrm{M}$ is still lower that the EPA recommendation. We could clearly observe the marker band of $\sim 2108 \mathrm{~cm}^{-1}$ at micromolar concentrations of $\mathrm{Cu}^{2+}$. The detection limit may be expected to improve toward around $1 \mu \mathrm{M}$ by optimizing the experimental conditions, although there is a turning point to yield a higher slope above $\sim 5 \mu \mathrm{M}$.

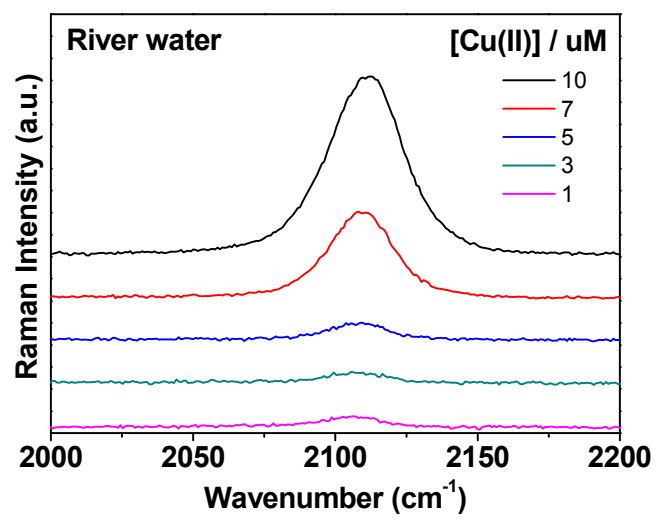

(a)

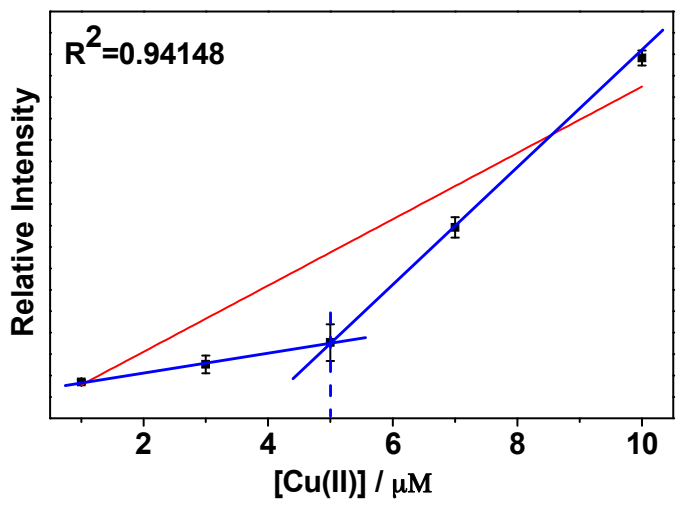

(b)

Figure 6. (a) A magnified view of the $\mathrm{CN}$ stretching region between 2000 and $2200 \mathrm{~cm}^{-1}$; (b) Intensity plot fitting the linear region on the $\left[\mathrm{Cu}^{2+}\right]$ concentration range of $1-10 \mu \mathrm{M}$ for river water. Three independent measurements were performed to yield the error bars.

\section{5. $\mathrm{Cu}^{2+}$ Ion Detection in Cancer Cells}

We attempted to detect the intracellular concentrations of $\mathrm{Cu}^{2+}$ ion in cellular media as depicted in Figure 7. We could observe the increase of the $\mathrm{CN}$ peaks in the $\mathrm{Cu}^{2+}$ ion concentration ranges between 5 and $20 \mu \mathrm{M}$, whereas we could not find any CN peaks for the control tests at $20 \mu \mathrm{M}$ of $\mathrm{K}^{+}$ion. Since the free $\mathrm{Cu}^{2+}$ ion inside cells may be much lower than that of the total copper ions, it is admitted that our methods may be limited in the case of the usages for the intracellular cellular free $\mathrm{Cu}^{2+}$ ion measurements under our experimental conditions.

Our current Raman spectroscopy-based ion detection approach may provide several advantages including better spectral resolution and multiplexing, which can be applied to the areas of cancer cell research, pharmaceutical identification, and characterization of dynamic interactions between nanoparticles and cells to overcome the limitation of the colorimetric method as depicted in Figure 2c.

Considering the unique spectral position of the $\mathrm{CN}$ band, the potential of our detection method is thought to be promising in comparison with the conventional SERS method, which may suffer from the spectral overlap in the congested wavenumber region. We shall keep improving the sensitivity by introducing novel nanostructures and optimizing the experimental parameters. Our method may provide a unique tool for detecting $\mathrm{Cu}^{2+}$ ions in an aqueous solution by means of Raman spectroscopy in a selective and sensitive manner. 


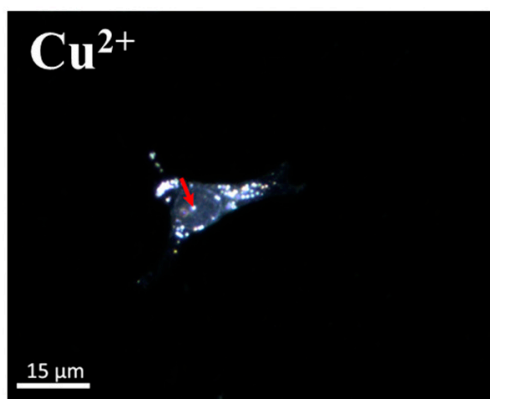

(a)

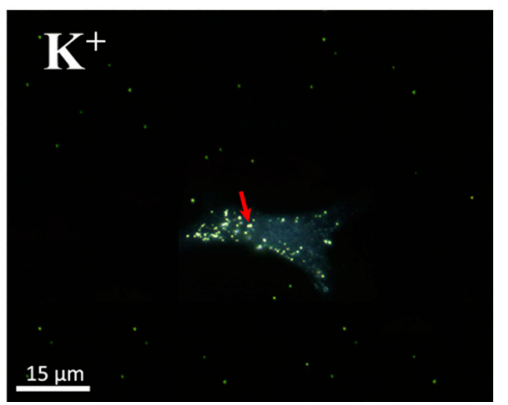

(b)

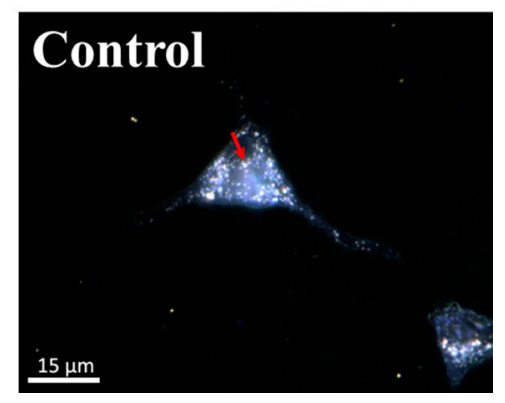

(c)

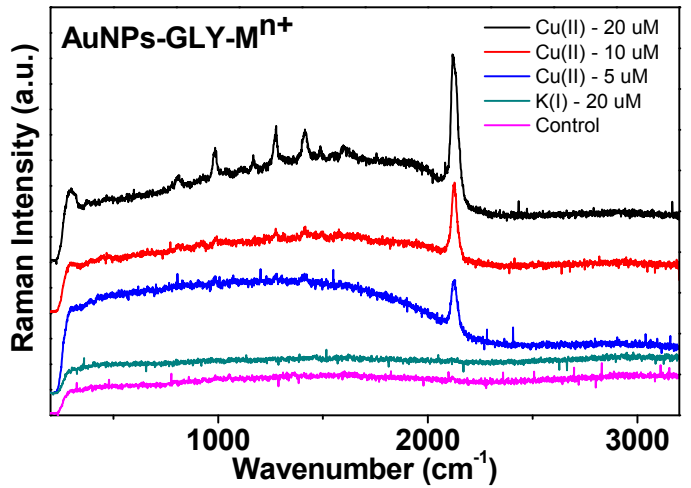

(d)

Figure 7. DFM cell images of HeLa cells treated with AuNPs-GLY-Cu ${ }^{2+}(20 \mu \mathrm{M})(\mathbf{a})$; AuNPs-GLY-K ${ }^{+}$ $(20 \mu \mathrm{M})(\mathbf{b})$; and AuNPs-GLY (c) for $24 \mathrm{~h}$ and subsequently the SERS spectra were observed. Only $\mathrm{Cu}^{2+}$ treated cells achieved the $\mathrm{CN}$ peak (d). The red arrows indicated the positions where the SERS spectra were taken.

\section{Conclusions}

We report a new detection method for $\mathrm{Cu}^{2+}$ ions by referring to the $\mathrm{CN}$ band increase by means of SERS of the dissociation from GLY on hydrazine-adsorbed AuNPs. UV-Vis absorption spectra are also introduced to check the $\left[\mathrm{Cu}^{2+}\right]$-induced surface change to indicate the Au particle aggregation to result in the color change. The surface charge variation is characterized by means of zeta potential measurements. The cyanide band at $2108 \mathrm{~cm}^{-1}$ became prominent upon the increase of $\mathrm{Cu}^{2+}$ ions. The cyanide peak intensities may be correlated with the $\mathrm{Cu}^{2+}$ ion concentration. The other 15 ions of $\mathrm{Fe}^{3+}, \mathrm{Fe}^{2+}, \mathrm{Hg}^{2+}, \mathrm{Mg}^{2+}, \mathrm{Mn}^{2+}, \mathrm{Ni}^{2+}, \mathrm{Zn}^{2+}, \mathrm{Cr}^{3+}, \mathrm{Co}^{2+}, \mathrm{Cd}^{2+}, \mathrm{Pb}^{2+}, \mathrm{Ca}^{2+}, \mathrm{NH}_{4}{ }^{+}, \mathrm{Na}^{+}$, and $\mathrm{K}^{+}$have not produced such spectral changes as $\mathrm{Cu}^{2+}$. The detection limit based on the $\mathrm{CN}$ band is estimated to be as low as $2 \mu \mathrm{M}$ of $\mathrm{Cu}^{2+}$ ions in river water. Our method was found to correlate with the $\mathrm{Cu}^{2+}$ ions under intracellular conditions in cancer cells.

Acknowledgments: This work was supported by Basic Research Laboratories (BRL) through an NRF grant funded by the MSIP (No. 2015056354).

Author Contributions: S.J. and N.H.L. conceptualized the study. C.S. provided the insight of the ionic detection using novel materials. N.H.L. designed and conducted the experiments. N.H.L. and S.J. analyzed the data. All authors read and reviewed the manuscript.

Conflicts of Interest: The authors declare no conflict of interest.

\section{References}

1. March, G.; Nguyen, T.D.; Piro, B. Modified electrodes used for electrochemical detection of metal ions in environmental analysis. Biosensors 2015, 5, 241-275. [CrossRef] [PubMed]

2. Tong, L.; Wei, H.; Zhang, S.; Xu, H. Recent advances in plasmonic sensors. Sensors 2014, 14, 7959-7973. [CrossRef] [PubMed] 
3. Doria, G.; Conde, J.; Veigas, B.; Giestas, L.; Almeida, C.; Assunção, M.; Rosa, J.; Baptista, P.V. Noble metal nanoparticles for biosensing applications. Sensors 2012, 12, 1657-1687. [CrossRef] [PubMed]

4. Khandelwal, P.; Singh, D.K.; Sadhu, S.; Poddar, P. Study of the nucleation and growth of antibiotic labeled Au NPs and blue luminescent Au8 quantum clusters for $\mathrm{Hg}(2+)$ ion sensing, cellular imaging and antibacterial applications. Nanoscale 2015, 7, 19985-20002. [CrossRef] [PubMed]

5. Kassu, A.; Farley, C., III; Sharma, A.; Kim, W.; Guo, J. Effect of pore size and film thickness on gold-coated nanoporous anodic aluminum oxide substrates for surface-enhanced Raman scattering sensor. Sensors 2015, 15, 29924-29937. [CrossRef] [PubMed]

6. Yaman, Y.T.; Abaci, S. Sensitive adsorptive voltammetric method for determination of bisphenol A by gold nanoparticle/polyvinylpyrrolidone-modified pencil graphite electrode. Sensors 2016, 16, 756. [CrossRef] [PubMed]

7. Li, D.; Lv, P.; Zhu, J.; Lu, Y.; Chen, C.; Zhang, X.; Wei, Q. NiCu alloy nanoparticle-loaded carbon nanofibers for phenolic biosensor applications. Sensors 2015, 15, 29419-29433. [CrossRef] [PubMed]

8. Braidy, N.; Poljak, A.; Marjo, C.; Rutlidge, H.; Rich, A.; Jayasena, T.; Inestrosa, N.C.; Sachdev, P. Metal and complementary molecular bioimaging in Alzheimer's disease. Front. Aging Neurosci. 2014, 6, 138. [CrossRef] [PubMed]

9. Majedi, S.M.; Kelly, B.C.; Lee, H.K. Toward a robust analytical method for separating trace levels of nano-materials in natural waters: Cloud point extraction of nano-copper(II) oxide. Environ. Sci. Pollut. Res. Int. 2014, 21, 11811-11822. [CrossRef] [PubMed]

10. Brewer, G.J. Copper toxicity in the general population. Clin. Neurophysiol. 2010, 121, 459-460. [CrossRef] [PubMed]

11. U.S. Environmental Protection Agency. Risk Assessment, Management and Communication of Drinking Water Contamination; U.S. EPA 625/4-89/024; Environmental Protection Agency: Washington, DC, USA, 1989.

12. Sadollahkhani, A.; Hatamie, A.; Nur, O.; Willander, M.; Zargar, B.; Kazeminezhad, I. Colorimetric disposable paper coated with ZnO@ZnS core-shell nanoparticles for detection of copper ions in aqueous solutions. ACS Appl. Mater. Interfaces 2014, 6, 17694-17701. [CrossRef] [PubMed]

13. Yuan, Z.; Cai, N.; Du, Y.; He, Y.; Yeung, E.S. Sensitive and selective detection of copper ions with highly stable polyethyleneimine-protected silver nanoclusters. Anal. Chem. 2014, 86, 419-426. [CrossRef] [PubMed]

14. Weng, Z.; Wang, H.; Vongsvivut, J.; Li, R.; Glushenkov, A.M.; He, J.; Chen, Y.; Barrow, C.J.; Yang, W. Self-assembly of core-satellite gold nanoparticles for colorimetric detection of copper ions. Anal. Chim. Acta 2013, 803, 128-134. [CrossRef] [PubMed]

15. Tsoutsi, D.; Guerrini, L.; Hermida-Ramon, J.-M.; Giannini, V.; Liz-Marzán, L.M.; Wei, A.; Alvarez-Puebla, R.A. Simultaneous SERS detection of copper and cobalt at ultratrace levels. Nanoscale 2013, 5, 5841-5846. [CrossRef] [PubMed]

16. Li, F.; Wang, J.; Lai, Y.; Wu, C.; Sun, S.; He, Y.; Ma, H. Ultrasensitive and selective detection of copper (II) and mercury (II) ions by dye-coded silver nanoparticle-based SERS probes. Biosens. Bioelectron. 2013, 39, 82-87. [CrossRef] [PubMed]

17. Ernst, K.H.; Christmann, K. The interaction of glycine with a platinum (111) surface. Surf. Sci. 1989, 224, 277-310. [CrossRef]

18. Han, J.W.; James, J.N.; Sholl, D.S. Chemical speciation of adsorbed glycine on metal surfaces. J. Chem. Phys. 2011, 135, 034703. [CrossRef] [PubMed]

19. Colaneri, M.J.; Vitali, J.; Peisach, J. Aspects of structure and bonding in copper-amino acid complexes revealed by single-crystal EPR/ENDOR spectroscopy and density functional calculations. J. Phys. Chem. A 2009, 113, 5700-5709. [CrossRef] [PubMed]

20. Zhen, C.-H.; Sun, S.-G.; Fan, C.-J.; Chen, S.-P.; Mao, B.-W.; Fan, Y.-J. In situ FTIRS and EQCM studies of glycine adsorption and oxidation on $\mathrm{Au}(111)$ electrode in alkaline solutions. Electrochim. Acta 2004, 49, 1249-1255. [CrossRef]

21. Hu, Q.; Tay, L.L.; Noestheden, M.; Pezacki, J.P. Mammalian cell surface imaging with nitrile-functionalized nanoprobes: Biophysical characterization of aggregation and polarization anisotropy in SERS imaging. J. Am. Chem. Soc. 2007, 129, 14-15. [CrossRef] [PubMed]

22. Lin, L.; Tian, X.; Hong, S.; Dai, P.; You, Q.; Wang, R.; Feng, L.; Xie, C.; Tian, Z.Q.; Chen, X. A bioorthogonal Raman reporter strategy for SERS detection of glycans on live cells. Angew. Chem. Int. Ed. Engl. 2013, 52, 7266-7271. [CrossRef] [PubMed] 
23. Cong, V.T.; Ganbold, E.-O.; Saha, J.K.; Jang, J.; Min, J.; Choo, J.; Kim, S.; Song, N.W.; Son, S.J.; Lee, S.B.; et al. Gold nanoparticle silica nanopeapods. J. Am. Chem. Soc. 2014, 136, 3833-3841. [CrossRef] [PubMed]

24. Ly, N.H.; Oh, C.H.; Joo, S.W. A submicromolar Cr(III) sensor with a complex of methionine using gold nanoparticles. Sens. Actuators B Chem. 2015, 219, 276-282. [CrossRef]

25. Ly, N.H.; Joo, S.-W. Zn(II)-concentration dependent Raman spectra in the dithizonecomplex on gold nanoparticle surfaces in environmental water samples. Appl. Surf. Sci. 2015, 356, 1005-1011. [CrossRef]

26. Ly, N.H.; Joo, S.-W. Silver nanoparticle-enhanced resonance Raman sensor of chromium(III) in seawater samples. Sensors 2015, 15, 10088-10099. [CrossRef] [PubMed]

27. Moulder, J.F.; Stickle, W.F.; Sobol, P.E.; Bomben, K.D. Handbook of X-ray Photoelectron Spectroscopy; Physical Electronics Inc.: Chanhassen, MN, USA, 1995.

28. Kumar, S.; Rai, A.K.; Singh, V.B.; Rai, S.B. Vibrational spectrum of glycine molecule. Spectrochim. Acta A 2005, 61, 2741-2746. [CrossRef] [PubMed]

29. Shi, Y.; Wang, L. Collective vibrational spectra of $\alpha$-and $\gamma$-glycine studied by terahertz and Raman spectroscopy. J. Phys. D Appl. Phys. 2005, 38, 3741-3745. [CrossRef]

30. Podstawka, E.; Ozaki, Y.; Proniewicz, L.M. Part I: Surface-enhanced Raman spectroscopy investigation of amino acids and their homodipeptides adsorbed on colloidal silver. Appl. Spectrosc. 2004, 58, 570-580. [CrossRef] [PubMed]

31. Durig, J.R.; Griffin, M.G.; Macnamee, R.W. Raman spectra of gases. XV: Hydrazine and hydrazine-d 4 . J. Raman Spectrosc. 1975, 3, 133-141. [CrossRef]

32. Braibanti, A.; Dallavalle, F.; Pellinghelli, M.A.; Leporati, E. The nitrogen-nitrogen stretching band in hydrazine derivatives and complexes. Inorg. Chem. 1968, 7, 1430-1433. [CrossRef]

33. Sheets, R.W.; Blyhokler, G. Isocyanate formation from adsorbed carbon monoxide and ammonia or hydrazine on vanadium, iron, and nickel. J. Phys. Chem. 1975, 79, 1572-1573. [CrossRef]

34. Ly, N.H.; Joo, S.-W. Surface anchoring mode-dependent hydrolysis reactions of hydrazone groups on gold examined by pH-dependent Raman spectroscopy. J. Raman Spectrosc. 2015, 46, 1082-1086. [CrossRef]

35. Oraby, E.A.; Eksteen, J.J. The selective leaching of copper from a gold-copper concentrate in glycine solutions. Hydrometallurgy 2014, 150, 14-19. [CrossRef]

36. Cho, K.; Jang, Y.S.; Gong, M.-S.; Kim, K.; Joo, S.-W. Determination of cyanide species in silver and gold plating solutions by Raman spectroscopy. Appl. Spectrosc. 2002, 56, 1147-1151. [CrossRef]

37. Li, G.; Luo, Y. Preparation and characterization of dendrimer-templated Ag-Cu bimetallic nanoclusters. Inorg. Chem. 2008, 47, 360-364. [CrossRef] [PubMed]

38. Bowmaker, G.A.; Kennedy, B.J.; Reid, J.C. Crystal structures of AuCN and AgCN and vibrational spectroscopic studies of AuCN, AgCN, and CuCN. Inorg. Chem. 1998, 37, 3968-3974. [CrossRef] [PubMed] 